\title{
Efecto de la concentración productiva sectorial y del gasto sobre la Productividad en Loretor
}

\author{
Effects of sectorial productive concentration and spending \\ on productivity in Loreto
}

\author{
Alexci Igor Chong Ríos ${ }^{2}$ \\ Universidad Nacional de la Amazonía Peruana \\ igorchong@hotmail.com \\ German Vladimir Chong Ríos ${ }^{3}$ \\ Universidad Nacional de la Amazonía Peruana \\ vladimir.chong@gmail.com
}

Recibido: 13/11/2019 - Aceptado: 29/12/2020 - Publicado: 17/02/2021

\begin{abstract}
RESUMEN
El estudio evalúa la hipótesis que Loreto presenta alta concentración productiva y ésta impacta negativamente en la producción, y que la ejecución del gasto público como la concentración por sector tienen escaso efecto sobre la eficiencia económica regional. Los resultados encuentran moderada concentración productiva por sector económico, así como un impacto negativo de la concentración en la producción y un escaso impacto en la productividad. Un aumento de 1\% en el gasto traslada en promedio $0.1575 \%$ al incremento en la productividad. La participación en el PBI de Loreto es impulsada por el gasto del sector público, lo que explica la persistente penúltima posición en el índice de competitividad regional.
\end{abstract}

(C) Los autores. Este artículo es publicado por Pensamiento Crítico de la Facultad de Ciencias Económicas, Universidad Nacional Mayor de San Marcos. Este es un artículo de acceso abierto, distribuido bajo los términos de la licencia Creative Commons Atribucion - No Comercia_Compartir Igual 4.0 Internacional. (http://creativecommons.org/licenses/by-nc-sa/4.0/) que permite el uso no comercial, distribución y reproducción en cualquier medio, siempre que la obra original sea debidamente citada. 
Palabras clave: Producción regional; productividad regional; concentración por sectores productivos; ejecución del gasto; índice de Herfindahl - Hirshman; eficiencia económica.

JEL: R11, H7, R5.

\section{ABSTRACT}

The study evaluates the hypothesis that Loreto has a high productive concentration and this negatively impact production and that the execution of public spending as well as the concentration by sector have little effect on regional economic efficiency. The results find moderate productive concentration by economic sector as well as a negative impact of the concentration on production and a low impact on productivity. A $1 \%$ increase in spending translates on average $0.1575 \%$ to the increase in productivity. Loreto's participation in GDP is running by public sector spending, which explains the persistent penultimate position in the regional competitiveness index. Keywords: Regional production; regional productivity; concentration by productive sectors; execution of expenditure; Herfindahl - Hirshman index; economic efficiency. JEL: R11, H7, R5. 


\section{INTRODUCCIÓN}

El Departamento de Loreto es el más extenso del país $(28,7 \%$ del territorio nacional), cuenta con la mayor diversidad maderable, es el mayor productor de petróleo, posee la diversidad acuícola más grande del país y muestra el reconocimiento oficial del Río Amazonas como nueva maravilla natural del mundo.

Sin embargo, dentro del índice de competitividad regional publicado por el Consejo Nacional de la Competitividad y Ranking de Competitividad (IPE, 2018) para ambos años, lo ubican en el puesto 23 de 24 departamentos del Perú. En otros términos, en un inamovible penúltimo puesto dentro de los últimos 13 años.

La figura 1 muestra el ranking de competitividad por regiones y la tabla 1 muestra los resultados del Índice de Competitividad Regional (ICR) al año 2015.

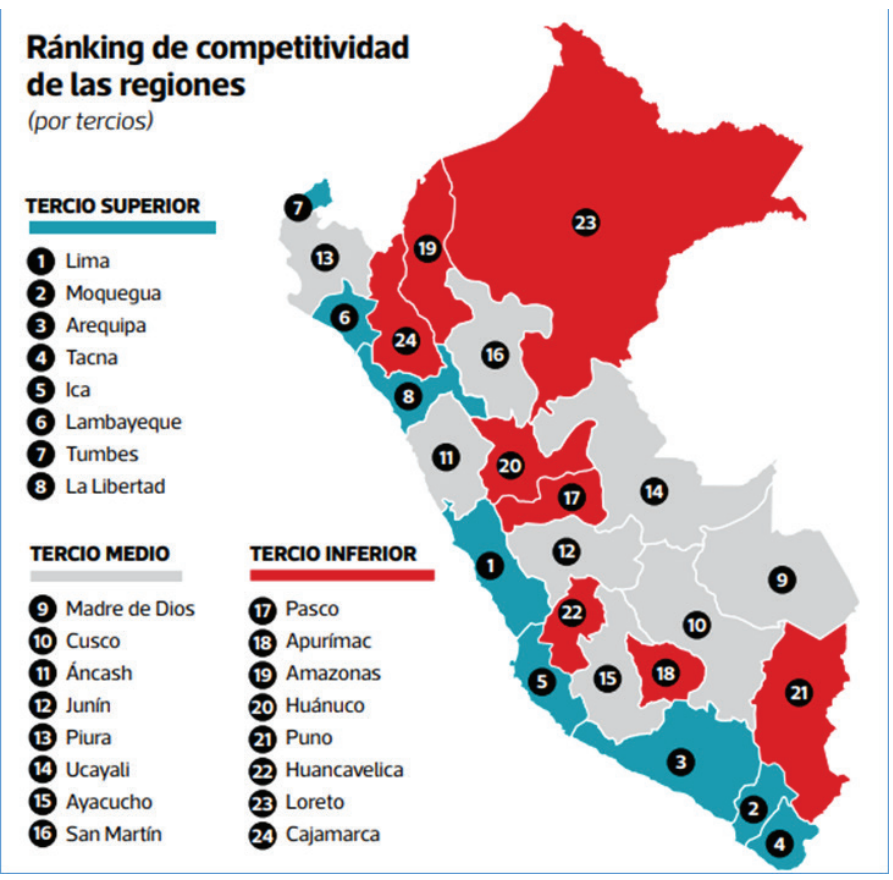

Figura 1. Ranking de Competitividad por regiones Fuente: Instituto Peruano de Economía. 
Tabla 1

Resultados del ICR 2007/08 2011/12 2016.2017

\begin{tabular}{|c|c|c|c|c|c|c|c|c|}
\hline Región & 2017 & 2016 & $2011 / 2012$ & $2010 / 2011$ & $2009 / 2010$ & $2008 / 2009$ & $2007 / 2008$ & $\begin{array}{c}\text { Variación } \\
2007 / 08 \text { - } \\
2011 / 12\end{array}$ \\
\hline Lima & $1^{\circ}$ & $1^{\circ}$ & $1^{\circ}$ & $1^{\circ}$ & $1^{\circ}$ & $1^{\circ}$ & $1^{\circ}$ & \\
\hline Moquegua & $2^{\circ}$ & $2^{\circ}$ & $2^{\circ}$ & $3^{\circ}$ & $3^{\circ}$ & $3^{\circ}$ & $3^{\circ}$ & $+1^{\circ}$ \\
\hline Arequipa & $4^{\circ}$ & $4^{\circ}$ & $3^{\circ}$ & $2^{\circ}$ & $2^{\circ}$ & $2^{\circ}$ & $2^{\circ}$ & $-1^{\circ}$ \\
\hline Ica & $5^{\circ}$ & $5^{\circ}$ & $4^{\circ}$ & $4^{\circ}$ & $4^{\circ}$ & $4^{\circ}$ & $4^{\circ}$ & \\
\hline Tacna & $3^{\circ}$ & $3^{\circ}$ & $5^{\circ}$ & $5^{\circ}$ & $5^{\circ}$ & $5^{\circ}$ & $5^{\circ}$ & \\
\hline Tumbes & $9^{\circ}$ & $10^{\circ}$ & $6^{\circ}$ & $6^{\circ}$ & $7^{\circ}$ & $7^{\circ}$ & $7^{\circ}$ & $+1^{\circ}$ \\
\hline La Libertad & $8^{\circ}$ & $9^{\circ}$ & $7^{\circ}$ & $8^{\circ}$ & $8^{\circ}$ & $8^{\circ}$ & $8^{\circ}$ & $+1^{\circ}$ \\
\hline Lambayeque & $7^{\circ}$ & $8^{\circ}$ & $8^{\circ}$ & $7^{\circ}$ & $6^{\circ}$ & $6^{\circ}$ & $6^{\circ}$ & $-2^{\circ}$ \\
\hline Piura & $13^{\circ}$ & $14^{\circ}$ & $9^{\circ}$ & $10^{\circ}$ & $10^{\circ}$ & $10^{\circ}$ & $11^{\circ}$ & $+2^{\circ}$ \\
\hline Junin & $14^{\circ}$ & $12^{\circ}$ & $10^{\circ}$ & $9^{\circ}$ & $9^{\circ}$ & $9^{\circ}$ & $9^{\circ}$ & $-1^{\circ}$ \\
\hline Ancash & $12^{\circ}$ & $13^{\circ}$ & $11^{\circ}$ & $11^{\circ}$ & $12^{\circ}$ & $11^{\circ}$ & $10^{\circ}$ & $-1^{\circ}$ \\
\hline Madre de Dios & $10^{\circ}$ & $7^{\circ}$ & $12^{\circ}$ & $12^{\circ}$ & $11^{\circ}$ & $12^{\circ}$ & $13^{\circ}$ & $+1^{\circ}$ \\
\hline Cuzco & $11^{\circ}$ & $11^{\circ}$ & $13^{\circ}$ & $13^{\circ}$ & $13^{\circ}$ & $13^{\circ}$ & $12^{\circ}$ & $-1^{\circ}$ \\
\hline Pasco & $17^{\circ}$ & $17^{\circ}$ & $14^{\circ}$ & $14^{\circ}$ & $14^{\circ}$ & $14^{\circ}$ & $14^{\circ}$ & \\
\hline San Martin & $15^{\circ}$ & $15^{\circ}$ & $15^{\circ}$ & $15^{\circ}$ & $15^{\circ}$ & $15^{\circ}$ & $15^{\circ}$ & \\
\hline Ucayali & $18^{\circ}$ & $18^{\circ}$ & $16^{\circ}$ & $16^{\circ}$ & $17^{\circ}$ & $17^{\circ}$ & $16^{\circ}$ & \\
\hline Ayacucho & $16^{\circ}$ & $16^{\circ}$ & $17^{\circ}$ & $17^{\circ}$ & $16^{\circ}$ & $16^{\circ}$ & $17^{\circ}$ & \\
\hline Puno & $22^{\circ}$ & $25^{\circ}$ & $18^{\circ}$ & $18^{\circ}$ & $18^{\circ}$ & $18^{\circ}$ & $18^{\circ}$ & \\
\hline Cajamarca & $24^{\circ}$ & $23^{\circ}$ & $19^{\circ}$ & $19^{\circ}$ & $20^{\circ}$ & $21^{\circ}$ & $21^{\circ}$ & $+2^{\circ}$ \\
\hline Apurimac & $21^{\circ}$ & $19^{\circ}$ & $20^{\circ}$ & $21^{\circ}$ & $21^{\circ}$ & $23^{\circ}$ & $23^{\circ}$ & $+3^{\circ}$ \\
\hline Huánuco & $20^{\circ}$ & $20^{\circ}$ & $21^{\circ}$ & $23^{\circ}$ & $23^{\circ}$ & $22^{\circ}$ & $22^{\circ}$ & $+1^{\circ}$ \\
\hline Amazonas & $19^{\circ}$ & $22^{\circ}$ & $22^{\circ}$ & $20^{\circ}$ & $19^{\circ}$ & $20^{\circ}$ & $19^{\circ}$ & $-3^{\circ}$ \\
\hline Loreto & $25^{\circ}$ & $22^{\circ}$ & $23^{\circ}$ & $22^{\circ}$ & $22^{\circ}$ & $19^{\circ}$ & $20^{\circ}$ & $-3^{\circ}$ \\
\hline Huancavelica & $23^{\circ}$ & $24^{\circ}$ & $24^{\circ}$ & $24^{\circ}$ & $24^{\circ}$ & $24^{\circ}$ & $24^{\circ}$ & \\
\hline
\end{tabular}

Fuente: Consejo Nacional de Competitividad.

Aún ante esta enjundia de recursos naturales y riqueza, los indicadores sociales no son alentadores. El Instituto Nacional de Estadística e Informática (INEI), al año 2017, reporta que Loreto contribuye en 1,7\% al PBI, el 56\% de la población cuenta con al menos una necesidad básica insatisfecha ${ }^{4}$, niveles de pobreza comprendidos en el intervalo de confianza 33,3 y 36,8 . El $56.4 \%$ de la población registra al menos un beneficiario en programas alimentarios, la tasa de analfabetismo es 7,3\%, la tasa de desnutrición crónica en niños menores de 5 años es de 23,8\% y el porcentaje de niños de 6 a 59 meses con anemia es de 52,1\%. 
Por el lado de la asignación presupuestal, durante el periodo 2007 al 2018, se incrementó en promedio el 196.6\%, ubicándose en el 2017 en 3,486'185.000 soles. La Región durante el periodo 2007 - 2017 ha crecido a una tasa promedio de $1.5 \%$ cifra inferior a la década de los 70 , la cual participó en la producción nacional con 3.1\%. Existen muchos factores que han determinado la reducción de este crecimiento, como ineficiencias del gasto, corrupción, crisis e irrupciones en la producción petrolera, escasa producción maderable por regulaciones en el sector forestal, etc.

Una característica fundamental es que la economía loretana, por sus características propias de aislamiento y baja inversión privada, se encuentra "sobrepoblada", existiendo unidades de producción llamados "sectores de subsistencia" donde se autoemplea el exceso de la oferta laboral. De este modo, es importante conocer si la concentración de la producción sectorial y la contribución del gasto público mejora la productividad como factor determinante en el crecimiento económico regional.

La evidencia empírica como cinturón protector de la teoría económica, requiere que se modelen variables que permitan explicar el comportamiento de la producción. Los modelos clásicos se enfocan básicamente a nivel de inversión y consumo (públicas y privadas). Sin embargo, es importante buscar en la enjundia teórica aspectos como la concentración y la eficiencia del gasto público como argumentos en el comportamiento de la producción.

De acuerdo a Gutierrez y Zamudio (2008): “El índice Herfindahl Hirschman se utiliza para medir la concentración del mercado. Este índice es sugerido como un indicador de estructura de mercado, dado que tiene en cuenta tanto el número de competidores como su participación relativa en el mismo" (p. 4). De forma análoga, a nivel macroeconómico la producción se distribuye por sectores y la concentración en la producción de bienes y servicios en un solo sector o pocos sectores no es socialmente óptimo. Conocer el peso de la producción por sector permitirá entender las características del sector y su influencia en la producción regional.

La escasa contribución al análisis y medición de los niveles de concentración por sectores productivos a la producción regional, así como la eficiencia del gasto público motivan realizar el presente estudio a fin de interpretar aspectos relevantes de la economía regional de Loreto. 
Estos aspectos a conocer generan las siguientes preguntas de investigación: ¿Cuál es el nivel de concentración por sector y su efecto en la producción regional? ¿Cuál es el efecto de la ejecución del gasto público y la concentración en la eficiencia económica regional? ¿Cuáles son los efectos del acceso al crédito y las exportaciones en la producción regional?

\section{METODOLOGÍA}

El enfoque de la investigación es cuantitativo, el alcance es descriptivo, correlacional y explicativo, y el diseño no experimental. A través de un análisis empírico se busca determinar el impacto de la concentración de mercado y eficiencia del gasto público en la producción regional.

Las hipótesis de estudio son:

1. Loreto presenta alta concentración productiva y ésta impacta negativamente en la producción.

2. La ejecución del gasto público y la concentración tiene escaso efecto sobre la eficiencia económica regional.

3. El acceso al crédito y las exportaciones impactan positivamente en la producción regional.

La información utilizada provino de fuentes primarias de las siguientes instituciones del país: Banco Central de Reserva del Perú (BCRP), Ministerio de Economía y Finanzas (MEF) e Instituto Nacional de Estadística e Informática (INEI). La información de la producción por sectores será capturada de los boletines mensuales y anuales que reporta la sucursal Iquitos del BCRP. La ejecución del gasto público se registra de la consulta amigable disponible en la página del portal MEF.

La información recolectada de las instituciones oficiales será utilizada para analizar el comportamiento de las variables en estudio. Para probar la primera hipótesis se siguieron dos rutas. La primera fue calcular el nivel de concentración productiva por sector.

Esto se analizó mediante el índice Herfindahl-Hirshman. La relación de cálculo es la siguiente: 


$$
\mathrm{IHH}=\Sigma\left(\mathrm{x}_{\mathrm{i}} / \mathrm{X}\right)^{2}
$$

Donde:

IHH: Concentración por sector

$\mathrm{x}_{\mathrm{i}}$ : Producción por sector

X : Producción regional total

El rango de decisión de acuerdo al criterio del Departamento de Justicia de los Estados Unidos, es la siguiente:

$$
\begin{array}{ll}
\text { IHH }<1500 & : \text { Baja concentración (Competitivo) } \\
1500 \leq \mathrm{IHH} \leq 2500 & : \text { Concentración moderada } \\
\mathrm{IHH}>2500 & : \text { Altamente concentrado. }
\end{array}
$$

La segunda ruta nos permitió conocer la variación porcentual promedio de la producción regional en función de la concentración por sector. Para tal fin los datos son transformados a logaritmos. Modelamos del siguiente modo:

$$
\operatorname{PROD}_{t}=\beta_{1}+\beta_{2 t} I H H+u_{t}
$$

Donde:

$\mathrm{PROD}_{\mathrm{t}:}$ Producción regional

IHH: Concentración por sector

$\beta_{2}$ : es el valor estimado por año del índice de concentración de mercado $\mathrm{u}_{\mathrm{t}}$ : es el error estocástico

La teoría predice que la estimación de la variable IHH presente signo negativo y significativo. Un signo negativo implica una covarianza inversa entre las variables por lo que una mayor concentración de mercado produce una menor producción regional. En sentido contrario, un signo positivo del estimador implica que, a mayor concentración por sector, mayor producción regional. 
Con respecto a la hipótesis 2 utilizamos la eficiencia económica entendida como la eficiencia técnica ${ }^{5}$. Esta variable usó como variable proxy la productividad laboral que es el cociente de la producción regional y la población económicamente activa ocupada en la región Loreto. Se espera que la variable gasto público muestre signo positivo y a un nivel de confianza al 95\%. Modelamos la relación del siguiente modo:

$$
\operatorname{PROD}_{\mathrm{t}}=\beta_{2 \mathrm{t}} \text { GASPUB }+\mathrm{u}_{\mathrm{t}}
$$

Donde:

PROD $_{\mathrm{t}}$ : Productividad laboral

GASPUB : Gasto público

$u_{t} \quad$ : es el error estocástico

Medimos además el efecto de la concentración sobre la productividad laboral. Para ambos casos omitimos la constante y aplicamos una regresión a través del origen. La fundamentación teórica de la omisión de la constante radica en darle una interpretación económica real al modelo propuesto. Las regresoras gasto público y concentración con valores cero, reflejarían que la productividad experimente cambios debido a otros factores. El modelo es el siguiente:

$$
\operatorname{PROD}_{\mathrm{t}}=\beta_{2 \mathrm{t}} \text { CONCENT }+\mathrm{u}_{\mathrm{t}}
$$

Donde:

PROD $_{\mathrm{t}} \quad$ : Productividad laboral

CONCENT : Concentración sectorial

$\mathrm{u}_{\mathrm{t}} \quad$ : es el error estocástico

En relación a la hipótesis 3 modelamos la regresión previamente tratando los datos de acceso al crédito y exportaciones a logaritmos. La variable acceso al crédito utiliza datos de personas que poseen una tarjeta de ahorros y se encuentran publicados en el portal INEI. Se espera que ambos estimadores muestren signo positivo con lo que se comprueba el impacto favorable hacia la producción nacional. El modelo a estimar es el siguiente: 


\section{Pensamiento Crítico Vol. 25. N²}

$$
\operatorname{PROD}_{\mathrm{t}}=\beta_{1}+\beta_{2 \mathrm{t}} \mathrm{X}+\beta_{3 \mathrm{t}} \mathrm{ACC}+\mathrm{u}_{\mathrm{t}}
$$

La variable X denota exportaciones, ACC acceso al crédito y PROD producción regional. Para probar la validez de los modelos se sometieron a pruebas de normalidad, homoscedasticidad y omisión de variables.

\section{MARCO TEÓRICO}

La participación del presupuesto público frente al PBI para la región Loreto $^{6}$ es cercano al $50 \%$ mientras que a nivel país la contribución del presupuesto público nacional frente al PBI nacional es del $21 \%$. De estas valoraciones podemos inferir que la producción regional en Loreto es fuertemente impulsada por el sector público. Este análisis general permite comprender porque la Región Loreto no logra superar el penúltimo puesto en el ranking de competitividad y nos acerca a entender la concentración productiva y gasto público como motor de la producción y productividad en la región.

\subsection{Concentración de mercado}

Goza de mayor aceptación e incluso fue concebido así, que el Índice Herfindahl Hirschman se utiliza para conocer la concentración existente en un determinado sector del mercado. El cálculo permite a las autoridades ajustar políticas económicas regulatorias en términos de mejorar la competencia en los mercados. No obstante, la generalización del indicador a los sectores de una economía no descalifica su aplicación ni generalización a los resultados, considerando que cada sector económico puede aproximarse a una unidad de negocios con resultados favorables o desfavorables.

Enfocar el análisis de la concentración implica ver el lado opuesto, la competencia. La relación entre concentración y competencia es ambigua. Por ejemplo, la búsqueda de costos más bajos dificulta la supervivencia de productores ineficientes que son obligados a fusionarse o salir del mercado, conduciendo a una mayor concentración de mercado. Por otro lado, existen sectores donde el aumento de la productividad de las empresas que la conforman, generalmente integradas en activos intangibles, desempeña un papel similar, de concentración. Siendo este análisis correcto, las empresas 
restantes deberían ser las más productivas y la concentración debería covariar positivamente con la productividad y la inversión intangible.

En contrapartida, de acuerdo a Philippon (2019) la concentración y la competencia se relacionan negativamente cuando las perturbaciones de los costos de entrada desempeñan un rol dominante. Esto se traduce en una falta o deficiencia de aplicación de leyes antimonopolio, barreras de entrada o la amenaza de comportamiento depredador por parte de las grandes empresas. De ser esto correcto, la concentración debería estar relacionada negativamente con la productividad y la inversión.

Estudios realizados por Covarrubias, Gutiérrez \& Philippon (2019) sobre la evolución de las utilidades, inversión y cuotas de mercado en las industrias estadounidenses en los últimos 40 años ha encontrado que durante la década de los 90's y con bajos niveles de concentración inicial, la evidencia muestra concentración eficiente impulsada por precios más rígidos, inversión intangible y aumento de productividad de los líderes. Sin embargo, después del 2000 la evidencia sugiere una concentración ineficiente, una competencia decreciente y barreras de entrada a medida que los líderes se afianzan más y la concentración se asocia con menor inversión, mayores precios, y menor crecimiento de la productividad.

El estudio de Covarrubias et al., (2019) permiten estilizar hechos considerados bien establecidos, aún lejos del consenso sobre lo que los está causando y lo que dice sobre la salud de la economía estadounidense. Las explicaciones la organizan en dos grupos.

\subsubsection{Buena Concentración.}

Los resultados sobre la tendencia observadas pueden explicarse como buenas fuentes de concentración como son a) incrementos en la elasticidad de sustitución (desde factores productivos puede entenderse como el trade off en la tasa marginal de sustitución, manteniendo el nivel de producción constante) y, b) cambios tecnológicos que conducen a rendimientos crecientes a escala y profundización del capital intangible. De acuerdo a Haskel y Westlake (2017) (citado por Covarrubias et al., 2019) defienden que los cambios tecnológicos que conducen a profundización del capital intangible, enfatizando como la escalabilidad y las sinergias del capital intangibles pueden conducir a rendimientos crecientes a escala. Bajo el enfoque de la 
tasa marginal de sustitución y profundización del capital intangible, la concentración es una buena noticia: Mas empresas productivas se expanden, pero la competencia permanece estable o aumenta.

\subsubsection{Mala concentración.}

Estas se pueden resumir como barreras crecientes a la competencia. Furman (2012) (citado por Covarrubias et al., 2019) señalan que la distribución de los rendimientos del capital se ha vuelto cada más sesgada y los altos rendimientos persisten, reflejándose esto en la creciente influencia de las rentas económicas y las barreras para la competencia. La concentración mala aumenta las rentas económicas y disminuye la innovación.

\subsection{Teorías de desarrollo económico local}

\section{a. Teorías del comercio.}

Las teorías clásicas del comercio internacional permiten esbozar una explicación sobre la concentración productiva por sectores.

Cuando un país puede producir una unidad de un bien con menos trabajo que otros países, decimos que este país tiene ventaja absoluta, mientras que la ley de la ventaja comparativa manifiesta que un país tiene ventaja si el costo de oportunidad en la producción de este bien en términos de otros bienes es inferior en este país de lo que es en otros países (Krugman y Obstfeld, 2006, p. 32).

El aspecto fundamental de la ventaja comparativa está en que una economía depende no sólo de su productividad en relación con la economía extranjera, sino también de la tasa salarial respecto a la tasa salarial extranjera.

\section{b. Teoría de la base económica regional.}

Esta teoría manifiesta que el desarrollo de una región está en función de los efectos e interacciones de una región con el resto de regiones.

El desarrollo de una región (o área específica local) depende de los efectos e interacciones que se producen en las actividades de la región un grupo de sectores o actividades denominados sectores básicos sobre el resto de actividades o sectores denominados sectores no 
básicos. Lo que impulsa el desarrollo de la región es el desarrollo de los sectores básicos cuyos productos son demandados fundamentalmente por regiones externas a la ubicación de los sectores básicos. El sector (o sectores) básico(s) representa(n) el sector "exportador" de la región (Tello, 2006, p. 37).

La principal actividad económica de la región Loreto lo constituye el sector hidrocarburos con una participación de crudo aproximada al 42\% a nivel nacional.

\section{c. Teoría neoclásica del desarrollo regional.}

La teoría económica neoclásica ha proporcionado la base sobre la cual las políticas económicas para el desarrollo regional posterior a la Segunda Guerra Mundial han tendido a centrarse de una forma u otra en la función de producción (trabajo y capital) y en las respuestas del estado a través de una gama de políticas económicas y no económicas. En este marco, la producción Q es producido por dos inputs, capital (K) y trabajo (L).

$$
Q=f(K, L)
$$

Este simple modelo de dos factores puede ser usado para medir la productividad del capital y del trabajo en una economía regional. El modelo puede ser expandido para incluir otras variables o factores, como la tecnología (T) u otras variables como el aprendizaje. La ecuación aumentada es.

$$
Q=f(K, L, T \ldots)
$$

De acuerdo a Richardson (1973): "El modelo neoclásico ha proporcionado una utilidad básica para entender las implicancias del cambio en capital y trabajo en la eficiencia económica de naciones y regiones". Sin embargo, no explica adecuadamente cómo la productividad, eficiencia y otros valores relacionados con la aplicación de mano de obra, capital y tecnología afectan el desarrollo económico, especialmente en la economía regional. Por tanto, la teoría neoclásica no identifica ni explica adecuadamente el comportamiento o factores que dan la definición de desarrollo económico regional o procesos de desarrollo económico.

Para complementar, de acuerdo a (Blakey, Lee, \& Lane, 1994) define desarrollo económico regional como: 
Un proceso en el cual un gobierno local u organizaciones basados en comunidad están comprometidos para estimular o mantener actividades comerciales o laborales. La principal meta del desarrollo económico regional es estimular las oportunidades de empleo en sectores que mejoren a la comunidad, utilizando mano de obra, recursos naturales e institucionales.

\section{d. Teoría de la Base Económica e Interdependencia de Sectores.}

La interacción entre las diversas herramientas de análisis contribuyó a un enfoque sobre la inter dependencia por sectores:

La teoría de la base económica ha sido sujeta de diversas modificaciones y extensiones muchas de ellas relacionadas a las herramientas económicas existentes en el desarrollo de la teoría económica. En su versión original, los sectores básicos y no básicos eran independientes y no existía interdependencia entre sectores. [...]. Un segundo grupo de extensiones toma en cuenta la interdependencia entre diversas regiones. A estos modelos se les denominan modelos de impacto multi-regionales. Herramientas econométricas también ha sido introducidas en estos dos grupos de extensiones con la denominación de modelos integrados econométricos y de matriz insumo productos. Un cuarto grupo de extensiones utiliza las herramientas de modelos computables de equilibrio general. La literatura de las extensiones ha sido resumida por Loveridge (2004), NijkampRietveld-Snickars (1987) y Hewings-Jensen (1987) (Tello, 2006, p. 42).

\subsection{Eficiencia del gasto público.}

El 1 de diciembre del 2016 entro en vigencia el Sistema Nacional de Programación Multianual y Gestión de Inversiones, conocido como INVIERTE.PE y a diferencia de su antecesor (SNIP) que enfocaba su ejecución en rentabilidad social, el nuevo sistema dirige su atención al cierre de brechas sociales y económicas. Aunque la finalidad del SNIP era certificar la calidad de los proyectos de inversión públicas la búsqueda de simplificar los procesos innovo el nuevo sistema presupuestal del estado. 
Sin embargo, la medición del logro de los objetivos del gasto no es fácil de cuantificar. De acuerdo a Porto (2018) los conceptos de eficiencia, productividad y calidad aplicados al sector público pueden ser dimensiones difíciles de medir. Gupta, Honjo, \& Verhoeven (1997) afirma:

Los estudios de medición del desempeño del sector público han seguido distintos enfoques. En un primer enfoque se han utilizado medidas por el lado de los insumos para proveer bienes: cantidad de empleados en cada actividad, gasto en cada actividad, etc. Estas medidas adolecen de fallas, ya que pueden existir ineficiencias traducidas en empleo, gasto, etc., que quedan ocultas en las medidas. En un segundo enfoque se ha utilizado la producción de bienes. Un tercer enfoque ha utilizado los resultados de las actividades del gobierno. Estos enfoques son parciales, ya que consideran por separado insumos, o productos, o resultados (p. 43).

En el Perú, con la promulgación del decreto de urgencia 005-2018 las medidas de eficiencia del gasto para el impulso económico se enmarcan en reducciones y límites al gasto en bienes y servicios (seminarios, talleres, servicios de imagen, pasajes y publicidad, así como un uso adecuado de vehículos oficiales).

Por otro lado, el aumento del gasto público es conveniente como una medida de política contra cíclica a fin de aumentar la producción en tiempos de recesión. Este enfoque se complementa si consideramos que los subsidios a programas sociales y compensaciones a tarifas de servició público no tienen como contrapartida aumentos en la producción sino el de transferir recursos de una parte de la población a otra menos afortunada.

\section{a. Productividad y eficiencia.}

De acuerdo a Mostajo (2000):

La consecución de mayores niveles de productividad en el uso de los recursos públicos tiene relevancia tanto en un sentido microeconómico como en uno macroeconómico. Por un lado, la medición de la productividad de las instituciones públicas contribuye significativamente al control, análisis y crecimiento de la productividad, la reducción de costos, el incremento de beneficios directos por el 
aumento de los niveles de producción y una mejor calidad de bienes y servicios (p. 11).

De la mano con lo referenciado, Krugman indica que la productividad en el largo plazo lo es todo. Si el producto total crece más que el incremento en los factores de producción, la diferencia está explicada por un aumento en productividad. Elevar los niveles de productividad es considerado favorable en contraposición a elevar niveles de competitividad, ya que este último concepto es asociado al comercio y considerado equivocadamente como lo más importante del mercado. Krugman P. (1994) indica. "La competitividad es una palabra sin sentido, cuando se aplica a las economías nacionales y la obsesión con la competitividad es tanto errónea como peligrosa" (p. 34).

A largo plazo el aumento de la productividad permite cerrar brechas de déficit público, relajar recursos para reasignarlos y financiar nuevos programas y proyectos.

Para utilizar la productividad como medida de eficiencia, se evalúa el nivel de producción que se obtiene con una combinación de insumos determinada (productividad multifactor) o con un nivel determinado de un insumo particular. [...]. Los distintos niveles de eficiencia observados entre organizaciones similares se explican por diferencias en la cantidad e intensidad de uso del factor con el que se está midiendo la productividad: mayores niveles de producción por trabajador o por unidad de capital pueden originarse por mejores y más modernos equipos, trabajadores más motivados, tecnologías más avanzadas o estructuras organizacionales más efectivas. En el sector público, la medición de su productividad se hace básicamente a través de la estimación de la productividad de dos insumos básicos: el trabajo y el gasto público (Mostajo, 2000, p. 12).

\section{b. Productividad del gasto público.}

El enfoque es considerar a las actividades del gobierno como procesos productivos. Cualquiera sea la naturaleza del gasto, las instituciones y/o gobiernos regionales o locales gastan fondos públicos con el objetivo de ser usados eficientemente. Por tanto, se puede evaluar de la siguiente forma 1) Menor costo posible; por ejemplo, bajo el ámbito de la Ley de 
Contrataciones del Estado la idea es adquirir los bienes y servicios al menor costo. 2) Optimalidad en la combinación de bienes y servicios y 3) Gasto público sostenible y sustentable.

\section{c. Productividad del trabajo en el sector público.}

Mostajo (2000) sostiene:

Convencionalmente, la productividad se expresa en términos de la producción por trabajador-hora. Sin embargo, la PT en el sector gobierno mide la producción de bienes y servicios públicos con relación a un insumo trabajo medido en términos de trabajador por año y no de trabajador por hora. [...]. Así, la PT puede elevarse a través de: (a) mejor calidad de la fuerza de trabajo, es decir mejorías en la capacidad y habilidades que permiten a los trabajadores cumplir las mismas tareas en menos tiempo (mayor capital humano por trabajador a través de educación, entrenamiento y capacitación), (b) mayor cantidad y mejor calidad del stock de capital público promoviendo la inversión en equipos y estructura, e infraestructura pública, (c) mejores y nuevas tecnologías que incrementen la eficiencia en el uso de los factores de producción, y (d) fomento de la competencia en los mercados a través de un marco regulatorio adecuado que promueva, simultáneamente, el logro más eficaz de objetivos y mayor eficiencia en la economía (p. 14).

\section{RESULTADOS}

La tabla 2 muestra información de la producción por actividad económica en la región Loreto, para el periodo 2007 - 2017.

El sector petróleo gas y minerales es el sector con mayor participación con una media en miles de soles de S/. 2’053.011 seguido del sector comercio con una producción promedio de S/. 1'239.084. Ambos sectores a la vez muestran mayor variabilidad productiva (S/ 798.980 y S/. 918.687, respectivamente).

Así mismo, el sector pesca y acuicultura como electricidad gas y agua son las que concentran menor producción. La tabla 3 muestra lo indicado. 
Pensamiento Crítico Vol. 25. N²

\begin{tabular}{|c|c|c|c|c|c|c|c|c|c|c|c|c|}
\hline & 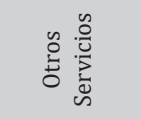 & $\begin{array}{l}\hat{O} \\
\text { N } \\
\text { N } \\
\text { N } \\
\text { - }\end{array}$ & 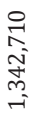 & $\begin{array}{l}\text { ñ } \\
\text { Nิ } \\
\text { ma } \\
\text { - }\end{array}$ & 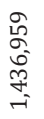 & 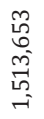 & 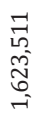 & 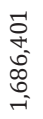 & 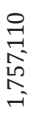 & 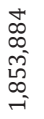 & 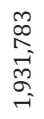 & 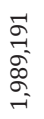 \\
\hline & 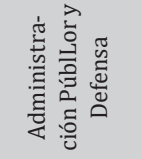 & 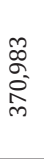 & 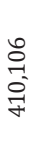 & 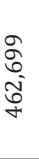 & $\begin{array}{l}\text { స̃ } \\
\text { f゙ } \\
\text { in }\end{array}$ & $\begin{array}{l}20 \\
0 \\
0 \\
0 \\
\text { ñ }\end{array}$ & 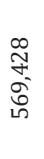 & $\begin{array}{l}\stackrel{0}{0} \\
\stackrel{-}{0} \\
\stackrel{0}{n}\end{array}$ & \begin{tabular}{l}
$\vec{\sigma}$ \\
مे \\
\multirow{\sigma}{\sigma}{}
\end{tabular} & $\begin{array}{l}\hat{\tilde{O}} \\
\text { oे } \\
\vec{\sigma}\end{array}$ & $\begin{array}{l}\text { f } \\
\infty \\
\text { ○े } \\
\text { Hू }\end{array}$ & $\begin{array}{l}m \\
\tilde{m} \\
\vec{\sigma} \\
\sigma\end{array}$ \\
\hline & 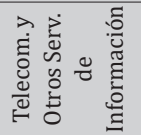 & 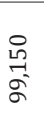 & 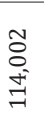 & 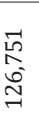 & 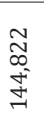 & 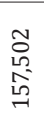 & 总 & $\begin{array}{l}\text { I } \\
\stackrel{2}{\sim} \\
\stackrel{-}{-}\end{array}$ & \begin{tabular}{l}
$\stackrel{L}{2}$ \\
m \\
\multirow{A}{N}{} \\
N
\end{tabular} & $\begin{array}{l}\infty \\
\stackrel{0}{0} \\
\stackrel{N}{N} \\
\text { N }\end{array}$ & $\begin{array}{l}\stackrel{\sim}{N} \\
\sim \\
\stackrel{N}{ }\end{array}$ & 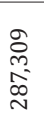 \\
\hline & 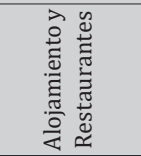 & 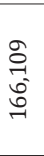 & 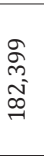 & 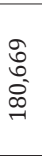 & $\begin{array}{l}\infty \\
\infty \\
m \\
\text { Lొ } \\
\stackrel{\sigma}{\sigma}\end{array}$ & $\begin{array}{l}\hat{\hat{\sigma}} \\
\stackrel{\sim}{N} \\
\vec{N}\end{array}$ & 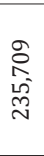 & $\begin{array}{l}\overrightarrow{\mathrm{N}} \\
\text { مै } \\
\overrightarrow{\mathrm{N}} \\
\text { N }\end{array}$ & $\begin{array}{l}\text { Ln } \\
0 \\
\text { î } \\
\text { N }\end{array}$ & $\begin{array}{l}\hat{b} \\
\mathscr{o}^{\circ} \\
\stackrel{\text { N }}{ }\end{array}$ & 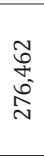 & 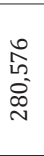 \\
\hline & 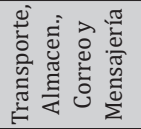 & $\begin{array}{l}\hat{f} \\
\infty \\
\text { ò } \\
\text { N }\end{array}$ & $\begin{array}{l}\text { ô } \\
0 \\
\text { Lे } \\
\text { Dे }\end{array}$ & 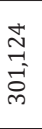 & $\begin{array}{l}\vec{m} \\
\stackrel{m}{2} \\
\stackrel{\vec{m}}{m}\end{array}$ & 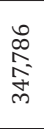 & 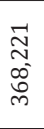 & $\begin{array}{l}\infty \\
\stackrel{\infty}{+} \\
\stackrel{-}{0} \\
\infty \\
m\end{array}$ & 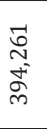 & $\begin{array}{l}\vec{b} \\
\text { m. } \\
\infty \\
0^{\circ}\end{array}$ & \begin{tabular}{l} 
Lొ \\
$\&$ \\
$\infty$ \\
\multirow{y}{*}{} \\
\end{tabular} & 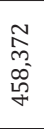 \\
\hline & @o & $\begin{array}{l}\hat{\infty} \\
0 \\
\infty^{\circ} \\
\vec{\sigma}\end{array}$ & $\begin{array}{l}\text { హ゙ } \\
\sigma \\
\text { よू } \\
\sigma\end{array}$ & $\begin{array}{l}\vec{m} \\
\text { مे } \\
\text { ूे }\end{array}$ & $\begin{array}{l}\infty \\
\stackrel{\infty}{N} \\
\exists \\
\exists \\
=\end{array}$ & 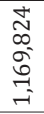 & 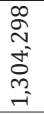 & \begin{tabular}{l}
$\hat{\infty}$ \\
+ \\
\multirow{2}{0}{} \\
m. \\
$\rightarrow$
\end{tabular} & 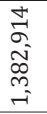 & 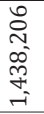 & $\begin{array}{l}\overrightarrow{1} \\
0 \\
0 \\
-1 \\
b \\
+ \\
-1\end{array}$ & 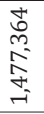 \\
\hline & 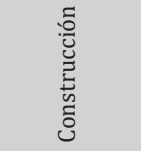 & 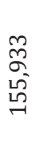 & 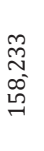 & 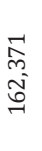 & 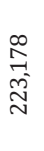 & 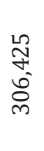 & 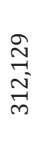 & 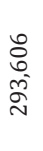 & $\begin{array}{l}\text { m } \\
\text { m̃ } \\
\text { 㞫 } \\
\text { N }\end{array}$ & $\begin{array}{l}\text { मे } \\
\text { ले } \\
\text { సે }\end{array}$ & $\begin{array}{l}\hat{a} \\
\hat{N} \\
\mathcal{N}^{\prime} \\
\text { N }\end{array}$ & 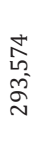 \\
\hline & 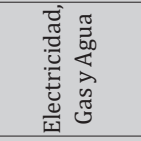 & \begin{tabular}{l}
$\infty$ \\
$\infty$ \\
\multirow{+}{*}{} \\
$\hat{\delta}$
\end{tabular} & $\begin{array}{l}\infty \\
\stackrel{\infty}{\circ} \\
\text { in } \\
\stackrel{1}{1}\end{array}$ & $\begin{array}{l}\overrightarrow{\mid} \\
\infty \\
\infty \\
\infty\end{array}$ & 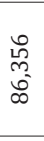 & $\begin{array}{l}\vec{\infty} \\
a \\
\text { ஸे } \\
\infty\end{array}$ & $\begin{array}{l}\text { m } \\
\stackrel{d}{0} \\
\stackrel{\infty}{\infty}\end{array}$ & $\begin{array}{l}\infty \\
\stackrel{0}{0} \\
\stackrel{-}{\infty}\end{array}$ & 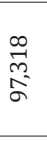 & 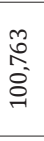 & $\begin{array}{l}\stackrel{2}{2} \\
\text {. } \\
\stackrel{+}{-}\end{array}$ & $\begin{array}{l}\hat{\sigma} \\
+ \\
+ \\
\text { +े }\end{array}$ \\
\hline $\begin{array}{l}\frac{2}{0} \\
6 \\
0\end{array}$ & 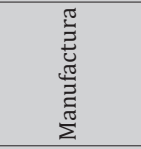 & 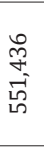 & 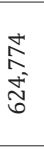 & 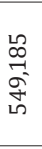 & $\begin{array}{l}\text { N } \\
\text { m } \\
\text { Li } \\
\text { on } \\
\omega\end{array}$ & 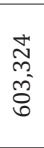 & $\begin{array}{l}\vec{m} \\
0 \\
0 \\
\text { +ै }\end{array}$ & 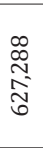 & 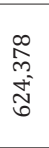 & 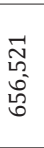 & $\begin{array}{l}\text { के } \\
0 \\
0 \\
\text { ఫै }\end{array}$ & 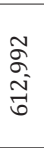 \\
\hline 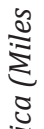 & 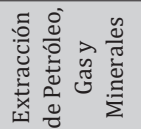 & 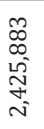 & 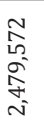 & 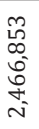 & 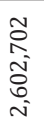 & 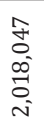 & 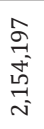 & 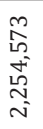 & $\begin{array}{l}\text { 今े } \\
\text { m. } \\
\text { Nิ } \\
\text { N } \\
\text { N }\end{array}$ & 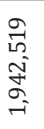 & 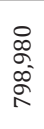 & 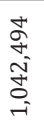 \\
\hline 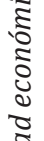 & 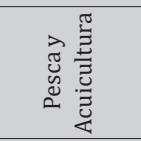 & $\begin{array}{l}\infty \\
\infty \\
\stackrel{0}{N} \\
\stackrel{N}{N}\end{array}$ & 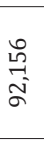 & $\begin{array}{l}\infty \\
\stackrel{\infty}{+} \\
\stackrel{-}{\sigma}\end{array}$ & $\begin{array}{l}\stackrel{2}{\stackrel{2}{2}} \\
\stackrel{+}{+} \\
\stackrel{-}{-}\end{array}$ & $\begin{array}{l}\hat{N} \\
\text { O } \\
\text { 尺े }\end{array}$ & $\frac{N}{\stackrel{N}{J}}$ & $\begin{array}{l}\text { مू } \\
\text { مे } \\
\text { స్}\end{array}$ & 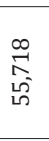 & 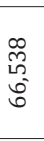 & $\begin{array}{l}\hat{\sigma} \\
\text { m. } \\
\text { హे }\end{array}$ & 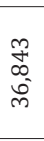 \\
\hline "ֶ̃ & 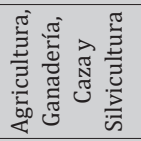 & $\begin{array}{l}\text { మొ } \\
\infty \\
\text { ஸ̂ } \\
\text { ஸ̂ }\end{array}$ & 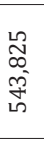 & 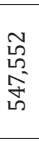 & $\begin{array}{l}\text { N్ } \\
\text { م̂ } \\
\text { Nิ } \\
\text { นิ }\end{array}$ & 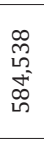 & 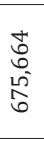 & $\begin{array}{l}m \\
\stackrel{m}{n} \\
\text { m. } \\
\stackrel{n}{n}\end{array}$ & $\begin{array}{l}\stackrel{\tilde{N}}{0} \\
\text { L్న } \\
\text { N }\end{array}$ & 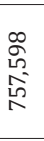 & 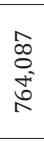 & $\begin{array}{l}8 \\
: \\
\text { L } \\
\text { L }\end{array}$ \\
\hline రั) & 妾 & 今े & $\begin{array}{l}\infty \\
\stackrel{\text { D }}{\text { D }}\end{array}$ & ڤे & 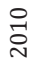 & $\vec{\sim}$ & $\underset{\sim}{\stackrel{N}{\sim}}$ & $\stackrel{m}{\stackrel{n}{\sim}}$ & $\underset{\sim}{\stackrel{\sim}{\sim}}$ & $\begin{array}{l}\text { Ln } \\
\text { 온 }\end{array}$ & $\stackrel{0}{\stackrel{1}{\sim}}$ & 官 \\
\hline
\end{tabular}


Tabla 3

Loreto: Estadística descriptiva por actividad económica (Miles de soles)

\begin{tabular}{|l|c|c|c|c|c|c|}
\hline Actividad Económica & Obs & Media & Std. Dev. & Min & Max & Participación \\
\hline Agricultura, ganadería caza y silvicutura & 11 & 652,345 & 94,201 & 525,853 & 764,087 & $8.26 \%$ \\
\hline Pesca y Acuicultura & 11 & 70,980 & 22,567 & 36,843 & 104,153 & $0.90 \%$ \\
\hline Extracción de Petróleo, Gas y Minerales & 11 & $2,053,011$ & 597,577 & 798,980 & $2,602,702$ & $26.01 \%$ \\
\hline Manufactura & 11 & 611,102 & 35,945 & 549,185 & 656,521 & $7.74 \%$ \\
\hline Electricidad, Gas y Agua & 11 & 88,835 & 12,064 & 67,488 & 104,469 & $1.13 \%$ \\
\hline Construcción & 11 & 238,464 & 59,833 & 155,933 & 312,129 & $3.02 \%$ \\
\hline Comercio & 11 & $1,239,084$ & 206,847 & 918,687 & $1,477,364$ & $15.70 \%$ \\
\hline Transporte, Almacen., Correo y Mensajería & 11 & 362,956 & 57,421 & 279,847 & 458,372 & $4.60 \%$ \\
\hline Alojamiento y Restaurantes & 11 & 228,379 & 42,409 & 166,109 & 280,576 & $2.89 \%$ \\
\hline Telecom. y Otros Serv. de Información & 11 & 183,387 & 62,176 & 99,150 & 287,309 & $2.32 \%$ \\
\hline Administración PúblLory Defensa & 11 & 545,795 & 100,861 & 370,983 & 691,303 & $6.91 \%$ \\
\hline Otros Servicios & 11 & $1,618,660$ & 245,642 & $1,272,307$ & $1,989,191$ & $20.51 \%$ \\
\hline
\end{tabular}

Fuente: Elaboración propia con datos del INEI

La figura 2 muestra que, de las doce actividades productivas, dos actividades muestran tendencia negativa en la producción. Estas dos actividades son: Extracción de petróleo gas y minerales y pesca y acuicultura. Durante el periodo de estudio la producción petrolera se contrajo en 57\%. Esta situación de reducción en la producción e incremento en la demanda de productos derivados se incrementa de manera preocupante ya que no existen proyectos prioritarios alternativos para diversificar el recurso energético.

El grado de concentración medido a través del Índice de Herfindhal-Hischman fue propuesto por Hirshman como medida alternativa al Índice de Gini para tratar de medir la concentración espacial de las actividades económicas. Más tarde Herfindahl lo introduce en la medición de la concentración empresarial de una determinada rama o actividad productiva. Por lo que también es conocido como índice Herfindahl-Hirshman, siendo el más utilizado para observar la concentración industrial debido a sus propiedades, ya que resultan muy interesantes desde el punto de vista teórico. Valores menores a 1500 indican una baja concentración. $1500 \leq \mathrm{IHH} \leq 2500$ indica concentración moderada. IHH > 2500 indica alta concentración. 
Pensamiento Crítico Vol. 25. $\mathrm{N}^{\circ} 2$
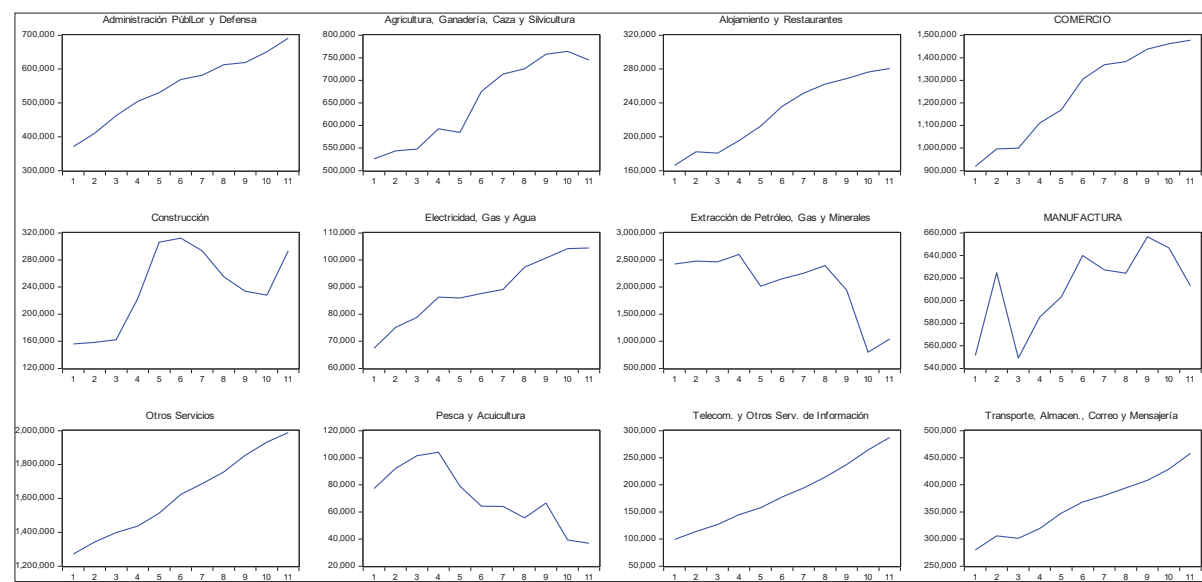

Electricidad, Gas y Agu
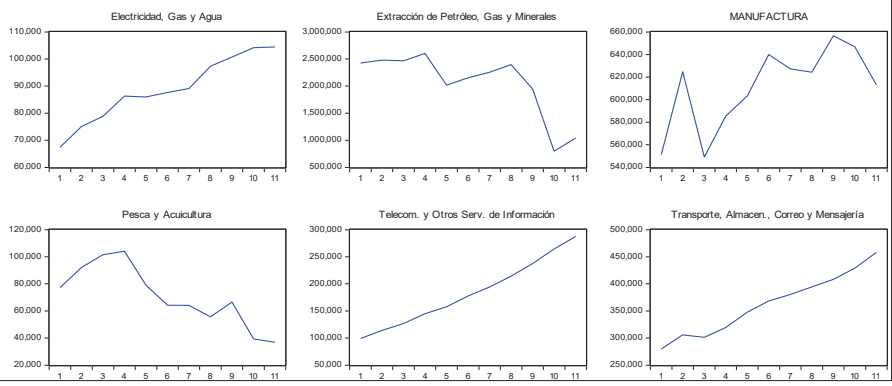

Figura 2. Evolución productiva por actividad económica (En miles de soles)

Elaborado en Eviews.

Las concentraciones productivas de la región Loreto medido a través del Índice IHH muestran valores entre 1400 a 1900, con un valor promedio de 1644. Esto se considera una concentración moderada. La tabla 4 ilustra lo indicado.

Tabla 4

Loreto: Producción regional y concentración productiva

\begin{tabular}{|c|c|c|}
\hline Año & $\begin{array}{c}\text { Producción Regional } \\
\text { (miles de soles) }\end{array}$ & Concentración \\
\hline 2007 & $6,910,964$ & 1,930 \\
\hline 2008 & $7,324,982$ & 1,860 \\
\hline 2009 & $7,374,935$ & 1,845 \\
\hline 2010 & $7,906,943$ & 1,800 \\
\hline 2011 & $7,608,889$ & 1,558 \\
\hline 2012 & $8,212,422$ & 1,557 \\
\hline 2013 & $8,505,693$ & 1,574 \\
\hline 2014 & $8,779,245$ & 1,607 \\
\hline 2015 & $8,583,456$ & 1,497 \\
\hline 2016 & $7,595,948$ & 1,443 \\
\hline 2017 & $8,019,487$ & 1,416 \\
\hline
\end{tabular}

Elaboración propia. 
En relación al efecto estadístico de la concentración por sector sobre la producción regional, el signo de la concentración es el esperado de acuerdo a la teoría. Un aumento de 1 punto porcentual en la concentración productiva genera una disminución en la producción en $0.42 \%$. La regresora es significativa y explica en un $37 \%$ el modelo bivariado. Los indicadores de violación a los supuestos se encuentran dentro de los parámetros establecidos, demostrando eficiencia, insesgadez y correcta especificación. La tabla 5 muestra los efectos estadísticos de la regresión.

Tabla 5

Efecto de la concentración sobre la producción regional

\begin{tabular}{|c|c|c|c|c|c|c|}
\hline Source & SS & df & MS & & Number of obs & 11 \\
\hline & & & & & $F(1,9)$ & 5.18 \\
\hline Model & 0.020600128 & 1 & 0.020600128 & & Prob $>$ F & 0.0488 \\
\hline \multirow[t]{2}{*}{ Residual } & 0.035759347 & 9 & 0.003973261 & & R-squared & 0.3655 \\
\hline & & & & & Adj R-squared & 0.2950 \\
\hline Total & 0.056359475 & 10 & 0.005635947 & & Root MSE & 0.06303 \\
\hline Prod_Reg & Coef. & Std. Err. & $\mathrm{t}$ & $\mathrm{P}>\mathrm{t}$ & \multicolumn{2}{|c|}{ [95\% Conf. Interval] } \\
\hline concent & -0.4171187 & 0.1831885 & -2.28 & 0.049 & -0.83152 & -0.002718 \\
\hline _cons & 18.96543 & 1.355649 & 13.99 & 0.000 & 15.89874 & 22.03212 \\
\hline
\end{tabular}

Prueba de diagnóstco

$\mathrm{J} / \mathrm{B} \quad 0.64$

White $\quad 0.56$

Ramsey $\quad 0.15$

$\mathrm{J} / \mathrm{B}=$ Test de Jarque Bera de Normalidad

White $=$ Prueba de Heteroscedasticidad

Ramsey $=$ Prueba de forma funcional

Elaborado en Stata.

Con respecto a la hipótesis 2 la tabla 6 muestra los datos consolidados de las variables que intervienen en el estudio. La producción regional muestra un incremento de 16\%, la PEA ocupada $14.28 \%$, la productividad regional $1.54 \%$, la ejecución presupuestal se incrementó en $196.4 \%$ y la concentración productiva por sector disminuyó en $26.6 \%$. Es alarmante ver que el incremento del presupuesto público se incrementó en 127 veces más que la productividad regional. 
Tabla 6

Datos consolidados

\begin{tabular}{|c|c|c|c|c|c|}
\hline Año & $\begin{array}{c}\text { Producción Regional } \\
\text { (miles de soles) }\end{array}$ & $\begin{array}{c}\text { PEA Ocupada } \\
\text { (Personas) }\end{array}$ & $\begin{array}{c}\text { Productividad } \\
\text { Regional }\end{array}$ & $\begin{array}{c}\text { Ejecución presupuestal } \\
\text { (miles de soles) }\end{array}$ & Concentración \\
\hline 2007 & $6,910,964$ & 441,971 & 15.637 & $1,176,412$ & 1,930 \\
\hline 2008 & $7,324,982$ & 447,200 & 16.380 & $1,462,330$ & 1,860 \\
\hline 2009 & $7,374,935$ & 448,300 & 16.451 & $1,513,146$ & 1,845 \\
\hline 2010 & $7,906,943$ & 455,600 & 17.355 & $1,771,064$ & 1,800 \\
\hline 2011 & $7,608,889$ & 462,300 & 16.459 & $2,267,930$ & 1,558 \\
\hline 2012 & $8,212,422$ & 485,400 & 16.919 & $2,413,923$ & 1,557 \\
\hline 2013 & $8,505,693$ & 499,200 & 17.039 & $2,679,792$ & 1,574 \\
\hline 2014 & $8,779,245$ & 493,500 & 17.790 & $2,866,934$ & 1,607 \\
\hline 2015 & $8,583,456$ & 495,400 & 17.326 & $2,869,040$ & 1,497 \\
\hline 2016 & $7,595,948$ & 500,100 & 15.189 & $2,963,970$ & 1,443 \\
\hline 2017 & $8,019,487$ & 505,100 & 15.877 & $3,486,565$ & 1,416 \\
\hline
\end{tabular}

Fuente: BCR, INEI.

Los datos a utilizar en la estimación son tratados a logaritmos y se muestran en la tabla 7. La Figura 3 muestra el comportamiento de las variables en el tiempo.

Tabla 7

Datos tratados a logaritmos

\begin{tabular}{|c|c|c|}
\hline Año & Productividad Regional & Ejecución presupuestal \\
\hline 2007 & 1.2115 & 7.0702 \\
\hline 2008 & 1.2149 & 7.2878 \\
\hline 2009 & 1.2152 & 7.3219 \\
\hline 2010 & 1.2190 & 7.4793 \\
\hline 2011 & 1.2147 & 7.7266 \\
\hline 2012 & 1.2160 & 7.7890 \\
\hline 2013 & 1.2161 & 7.8935 \\
\hline 2014 & 1.2196 & 7.9610 \\
\hline 2015 & 1.2175 & 7.9617 \\
\hline 2016 & 1.2073 & 7.9943 \\
\hline 2017 & 1.2105 & 8.1567 \\
\hline
\end{tabular}

Elaboración propia. 
La figura 3 ilustra una caída en la concentración productiva por sector. Esta caída coincide con la contracción del sector hidrocarburos y pesca y la tendencia creciente no interrumpida de ocho sectores como se muestra en la figura 2. Este comportamiento denota los resultados de una moderada concentración de acuerdo al índice IHH descrito anteriormente.

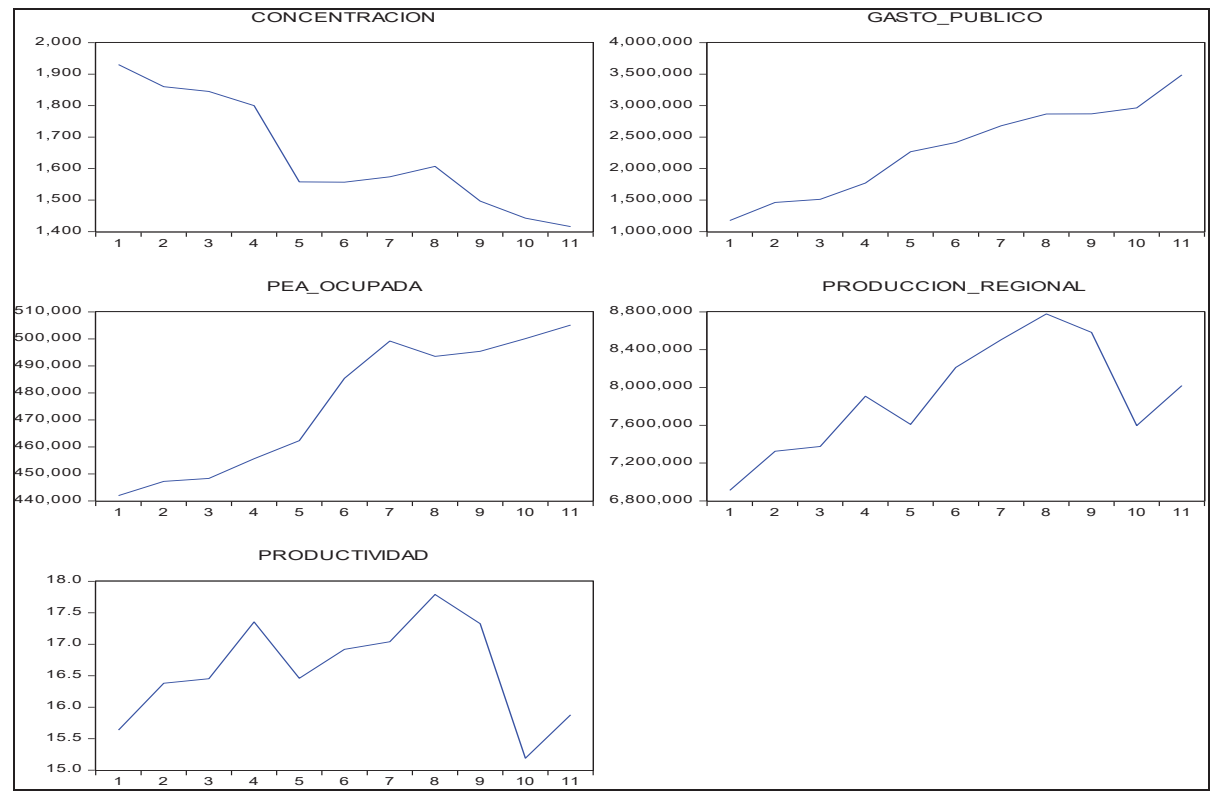

Figura 3. Evolución de las variables Elaborado en Eviews.

En cuanto a la dependencia estadística un incremento en 1 punto porcentual en el gasto público genera en promedio un impacto de $0.1575 \%$ en la productividad laboral. Por el lado de la concentración un incremento de éste en un punto porcentual genera un incremento en la productividad de $0.1641 \%$. Los resultados de las regresiones se ilustran en las tablas 8 y 9 .

Es importante notar un aparente resultado paradójico del efecto de la concentración por sectores sobre la producción y la productividad. En el primer caso la concentración tiene una covarianza negativa lo que significa que un incremento en la concentración genera una disminución en la producción. En el segundo caso, la covarianza es positiva el cual indica que un incremento en la concentración genera un incremento en la productividad. 
Pensamiento Crítico Vol. 25. N²

Tabla 8

Efecto del Gasto Público sobre la Productividad

Hipótesis 2

\begin{tabular}{|c|c|c|c|c|c|c|}
\hline Source & SS & df & MS & & Number of obs & 11 \\
\hline & & & & & $F(2,8)$ & 5199.11 \\
\hline Model & 16.20089 & 1 & 16.20089 & & Prob $>$ F & 0.0000 \\
\hline \multirow[t]{2}{*}{ Residual } & 0.0311609 & 10 & 0.0311609 & & R-squared & 0.9981 \\
\hline & & & & & Adj R-squared & 0.9979 \\
\hline Total & 16.232051 & 11 & 1.475641 & & Root MSE & 0.05582 \\
\hline PROD & Coef. & Std. Err. & $\mathrm{t}$ & $\mathrm{P}>\mathrm{t}$ & \multicolumn{2}{|c|}{ [95\% Conf. Interval] } \\
\hline GASPUB & 0.157568 & 0.002185 & 72.1 & 0.000 & 0.152699 & 0.1624371 \\
\hline \multicolumn{7}{|c|}{ Prueba de diagnóstco } \\
\hline $\mathrm{J} / \mathrm{B}$ & 0.6472 & & & & & \\
\hline White & 0.092 & & & & & \\
\hline
\end{tabular}

$\mathrm{J} / \mathrm{B}=$ Test de Jarque Bera de Normalidad

White $=$ Prueba de Heteroscedasticidad

Elaborado en Stata.

Tabla 9

Efecto de la concentración sectorial sobre la Productividad

Hipótesis 2

\begin{tabular}{|c|c|c|c|c|c|c|}
\hline & SS & df & MS & & Number of obs & 11 \\
\hline & & & & & $F(2,8)$ & 54391.82 \\
\hline Model & 16.229482 & 1 & 16.229482 & & Prob $>$ F & 0.0000 \\
\hline \multirow[t]{2}{*}{ Residual } & 0.0029838 & 10 & 0.0029838 & & R-squared & 0.9998 \\
\hline & & & & & Adj R-squared & 0.9998 \\
\hline Total & 16.232466 & 11 & 1.4756788 & & Root MSE & 0.01727 \\
\hline PROD & Coef. & Std. Err. & $\mathrm{t}$ & $\mathrm{P}>\mathrm{t}$ & \multicolumn{2}{|c|}{ [95\% Conf. Interval] } \\
\hline CONCENT & 0.164137 & 0.000704 & 233.22 & 0.000 & 0.1625691 & 0.1657054 \\
\hline
\end{tabular}

Prueba de diagnóstco

J/B $\quad 0.5291$

White $\quad 0.0769$

$\mathrm{J} / \mathrm{B}=$ Test de Jarque Bera de Normalidad

White $=$ Prueba de Heteroscedasticidad

Elaborado en Stata. 
El comportamiento de las tendencias se puede observar en la figura 5 y 6. En ambos casos el coeficiente de la pendiente es negativa lo que explica que las desviaciones de ambas variables con respecto a la media siguen la misma dirección. El resultado discrepante radica en que la curva de la productividad regional cambia de pendiente debido a que refleja el cociente de la producción sobre la PEA ocupada; sin embargo, se observa que el impacto de la concentración es marginal sobre la productividad regional.

\section{Producción regional}

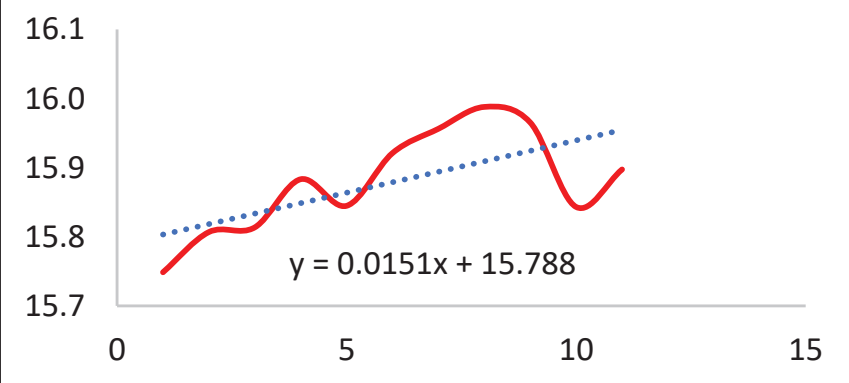

Figura 4. Evolución de la producción regional

Elaborado en Excel.

\section{Productividad regional}

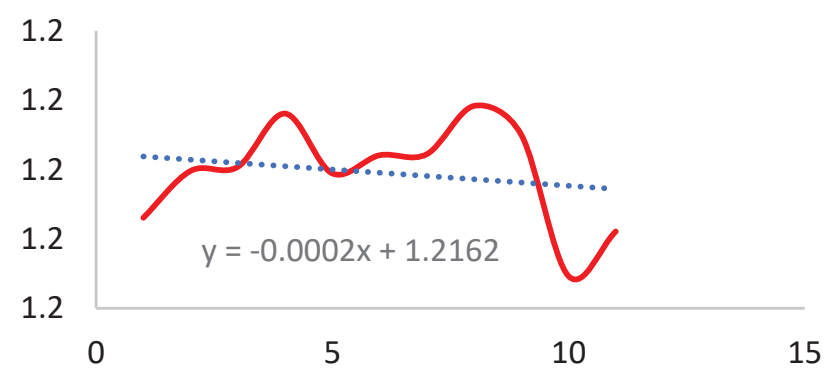

Figura 5. Evolución de productividad

Elaborado en Excel. 


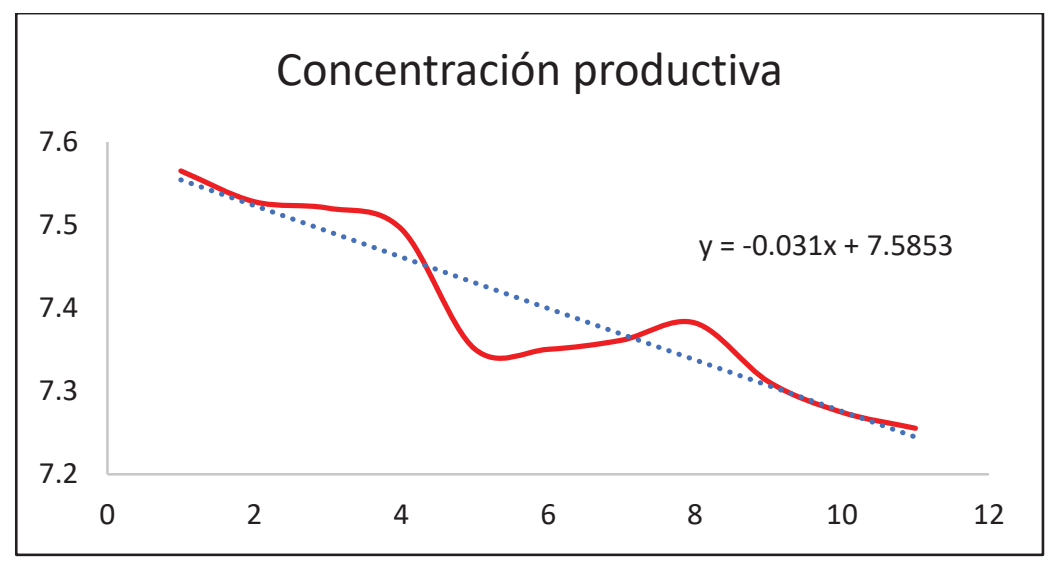

Figura 6. Evolución de la concentración productiva

Elaborado en Excel.

En relación a la hipótesis 3 los datos exportaciones y acceso al crédito previamente tratados a logaritmos, muestran una relación positiva. La variable exportaciones no es significativa. Las regresoras explican un $62 \%$ el comportamiento de la regresada y los supuestos del modelo medidos a través de los indicadores Jarque Bera (normalidad), test de White (homoscedasticidad) y Reset de Ramsey (correcta especificación) corroboran la capacidad predictiva del modelo. A nivel de logaritmos los resultados muestran la elasticidad de las variables. Un aumento de $1 \%$ en las exportaciones genera un incremento en la producción del $0.06 \%$, mientras que un aumento de $1 \%$ de personas que acceden a créditos genera un incremento en la producción en $0.3 \%$.

Tabla 10

Resultados de la estimación

Hipótesis 3

\begin{tabular}{lccllr}
\hline Source & SS & df & MS & Number of obs & $\mathbf{1 1}$ \\
\hline & & & & F(2, 8) & 6.51 \\
Model & 0.0349029 & 2 & 0.0174512 & Prob > F & 0.021 \\
Residual & 0.0214469 & 8 & 0.0026809 & R-squared & 0.6194 \\
& & & & Adj R-squared & 0.5242 \\
Total & 0.0563498 & 10 & 0.005635 & Root MSE & 0.05178 \\
& & & & & \\
\hline
\end{tabular}




\begin{tabular}{|c|c|c|c|c|c|c|}
\hline \multicolumn{7}{|c|}{ Tabla 10: Continuación } \\
\hline prod_regio $\sim 1$ & Coef. & Std. Err. & $\mathrm{t}$ & $\mathrm{P}>\mathrm{t}$ & \multicolumn{2}{|c|}{ [95\% Conf. Interval] } \\
\hline $\mathrm{X}$ & 0.0556547 & 0.0316708 & 1.76 & 0.117 & -0.0173783 & 0.1286876 \\
\hline acc & 0.2977915 & 0.0825382 & 3.61 & 0.007 & 0.1074580 & 0.488125 \\
\hline _cons & 6.30012 & 0.7518368 & 8.38 & 0.000 & 4.566381 & 8.033859 \\
\hline \multicolumn{7}{|c|}{ Prueba de diagnóstco } \\
\hline $\mathrm{J} / \mathrm{B}$ & \multicolumn{6}{|l|}{0.84} \\
\hline White & \multicolumn{6}{|l|}{0.21} \\
\hline Ramsey & \multicolumn{6}{|l|}{0.95} \\
\hline \multicolumn{7}{|c|}{$\mathrm{J} / \mathrm{B}=$ Test de Jarque Bera de Normalidad } \\
\hline \multicolumn{7}{|c|}{ White $=$ Prueba de Heteroscedasticidad } \\
\hline \multicolumn{7}{|c|}{ Ramsey = Prueba de forma funcional } \\
\hline
\end{tabular}

Elaborado en Stata.

\section{DISCUSIÓN}

El principal sector de la economía de Loreto (Hidrocarburos) declinó su producción en 52\%. Sin embargo, el aumento constante en la demanda de productos derivados incrementa las importaciones con consecuencias salidas de divisas, contribución a la presión en el déficit en la cuenta corriente de la balanza de pagos, reducción en canon y sobrecanon y desempleo en la región. Se requieren medidas orientadas a la búsqueda de nuevas fuentes energéticas.

El alarmante incremento en 126 veces más el presupuesto nacional frente a la productividad (192.37\% vs 1.54\%) manifiesta ineficiencia en el gasto público. Se requiere medidas de ajuste y control en el gasto.

La caída en el sector hidrocarburos y pesca muestra correlación inversa en el incremento de ocho sectores productivos. Este comportamiento explica la tendencia decreciente de la concentración medida a través del indicador IHH para los sectores de la economía Loretana.

Los continuos problemas presentados en el oleoducto Nor peruano, la antigüedad de los ductos en el sistema de transporte y la falta de exploración generan la caída productiva y subsecuente disminución en empleo, canon y sobrecanon. Cifras de la Sunat indican que a junio del 2018 se importaron 2,300 millones de dólares de petróleo, lo que nos ubica como país deficitario del recurso. 
El aporte de la actividad productivo forestal (madera aserrada y triplay) considerado como actividad no primaria del sector manufactura no recupera sus niveles de producción por las regulaciones implementadas a fin de evitar la tala ilegal.

El principal producto de exportación de Loreto es el Petróleo crudo y derivados cuyo destino principal es la Ciudad de Leticia ubicado en Colombia. Dentro de la teoría del comercio internacional Loreto aprovecha la ventaja absoluta de producción de petróleo en vista de los menores costos de producción. En efecto, el tipo de cambio del sol versus el peso colombiano evidencia mayor fortaleza del sol peruano.

En relación a la teoría de la base económica regional, Loreto es una región que importa productos básicos de otras regiones. El sector agropecuario, manufactura, avícola y otros son importados de otras regiones. El sector agrícola es solo para el abastecimiento interno. Por tanto, Loreto carece de una actividad base que le permita generar eslabones en otras actividades no básicas. La figura 7 muestra la cuenta corriente de Loreto de 1994 al 2019 donde se puede apreciar el desbalance entre exportaciones e importaciones.

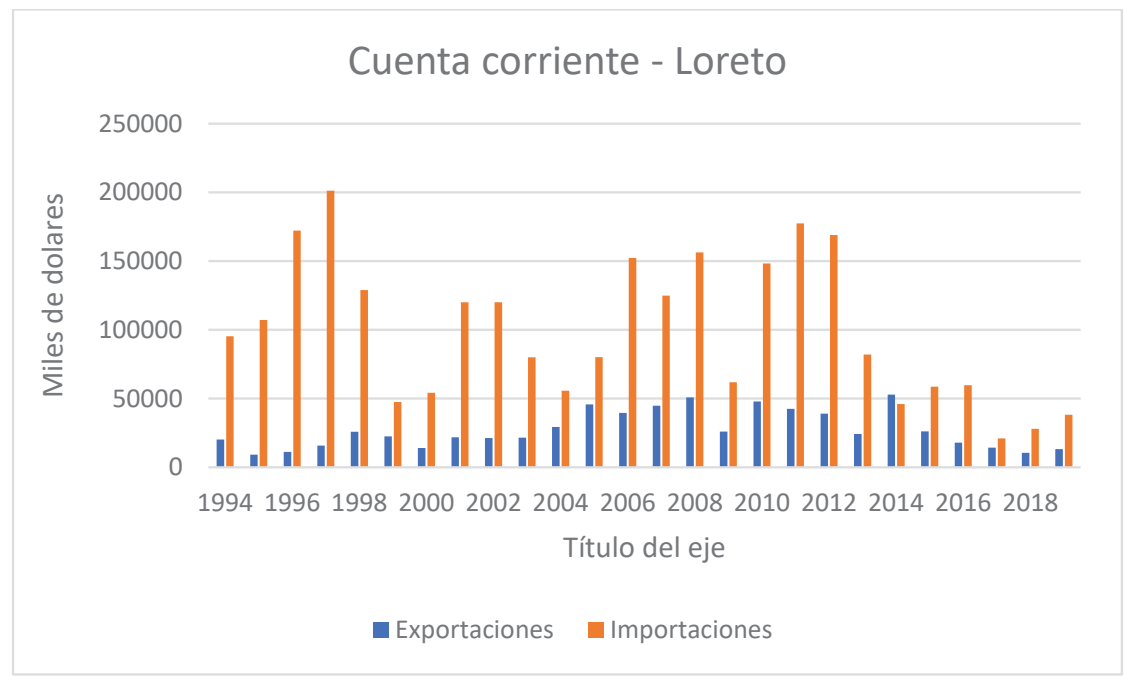

Figura 7. Cuenta corriente Loreto 1994 - 2017

Fuente: INEI. Sistema de información regional 


\section{CONCLUSIONES}

La economía de la región Loreto a nivel de sectores productivos presenta una moderada concentración productiva con un índice de Herfindahl- Hirshman de 1644 puntos. La tendencia es a una disminución en la concentración.

De los doce sectores de estudio el sector hidrocarburos y el sector pesca muestran tendencia a la baja. El primero disminuyo en $57 \%$ y el segundo en $52 \%$.

El efecto de la concentración regional sobre la producción es negativo. Un aumento de $1 \%$ en la concentración produce una disminución de la producción regional en $0.42 \%$.

El incremento del presupuesto público se incrementó en 127 veces superior a la productividad regional. La productividad durante el periodo de estudio se incrementó solo en 1,54\% mientras que el presupuesto público en $196,4 \%$.

Un incremento de $1 \%$ en el gasto público genera un aumento en la productividad en $0.1575 \%$, mientras que un incremento de $1 \%$ en la concentración produce un aumento de $0.1641 \%$ en la productividad regional.

Un aumento de 1\% en las exportaciones genera un incremento en la producción del $0.06 \%$, mientras que un aumento de $1 \%$ de personas que acceden a créditos genera un incremento en la producción en $0.3 \%$.

La contribución a la formulación de políticas públicas permite mostrar el decrecimiento del sector hidrocarburos y pesca, así como el impacto negativo de la concentración en la producción y el pequeño impacto en la productividad. Adicional a lo indicado, coloca en evidencia que cerca al $50 \%$ del presupuesto del gobierno regional y local (sin considerar programas sociales e instituciones autónomas del estado) contribuye a la producción regional. A modo de comparación a nivel nacional la contribución del presupuesto público al PBI nacional es cercana al 21\%, lo que evidencia que la economía regional de Loreto es impulsada básicamente por el sector público, lo que podría explicar el pernicioso penúltimo puesto en el ranking de competitividad. 
El decrecimiento de la producción petrolera en la región se ve afectada básicamente por tres factores: a) Toma y paralización forzada y rotura del oleoducto por comunidades nativas e indígenas asentadas en las zonas de explotación, b) agotamiento del recurso y, c) falta de inversión en exploración. El gobierno regional debe cuantificar, controlar e impulsar acuerdos con el sector privado a fin de evitar pérdida de empleos e ingresos para el desarrollo de la región Loreto.

Finalmente, aun cuando la concentración por sectores muestra una tendencia a declinar y este mantiene una covarianza negativa con la producción, es importante el apoyo e impulso por la autoridad nacional y regional al sector primario de la economía Loretana. El sector primario agrupa el sector agropecuario (yuca, maíz amarillo, arroz cascara, etc.), el sector pesca (de consumo humano) y el sector hidrocarburos. La producción es insuficiente para el abastecimiento local y se destaca que el impuso del sector primario al crecimiento económico regional es ingente, fundamental y estratégico para que el sector industrial se fortalezca y expanda.

\section{REFERENCIAS BIBLIOGRAFICAS}

Blakey, G., Lee, C., \& Lane, M. (1994). Human Resource Development Quarterly. Obtenido de Managment Development Programs: The Effect of Managment Level and Corporate Strategy: https://doi.org/10.1002/hrdq.3920050103

Covarrubias, M., Gutiérrez, G., \& Philippon, T. (2019). From Good to Bad Concentration? U.S. Industries Over the Past 30 Years. National Bureau of Economic Research. Obtenido de https://www.nber.org/system/files/working_papers/w25983/w25983.pdf

Gupta, S., Honjo, K., \& Verhoeven, M. (1997). The efficiency of government expenditures. Experiences in Africa. International Monetary Fund. Obtenido de https://www.imf.org/external/pubs/ft/wp/wp97153.pdf

Gutierrez, J., \& Zamudio, N. (2008). Medidas de Concentracion y Competencia. Colombia: Banco de la República. Obtenido de https://www.banrep.gov.co/docum/Lectura_finanzas/pdf/medidas.pdf

IPE. (Junio de 2018). Instituto Peruano de Economía. Obtenido de INCORE 2018 Índice de Competitividad Regional: https://www.ipe.org.pe/portal/incore2018-indice-de-competitividad-regional/ 
Krugman, P. (1994). Competitividad: Una peligrosa obsesión. Foreign Affairs. Obtenido de https://revistas.unal.edu.co/index.php/ede/article/ view/23735/24422

Krugman, P., \& Obstfeld, M. (2006). Economía internacional. Madrid: Pearson Education S.A.

Mostajo, R. (2000). Productividad del sector público, evaluación de la gestión del gasto público e indicadores de desempeño en Guatemala. Santiago de Chile: CEPAL.

Philippon, T. (2019). The Economics and Politics of Market Concentration. National Bureau of Economic Research. Obtenido de https://www.nber.org/ reporter/2019number4/economics-and-politics-market-concentration

\title{
Tello, M. (2006). Las Teorías del Desarrollo Económico Local y la Teoría y Práctica del Proceso de Descentralización en los Países en Desarrollo. . CENTRUM Católica.
}

\section{Notas al final}

1 La investigación busca contribuir mediante la investigación empírica en el Departamento de Loreto a fin de mejorar las políticas públicas regionales.

\begin{abstract}
2 Economista y Magister en Finanzas por la Universidad Nacional de la Amazonía Peruana. Doctor en Gestión Económica Global por la Universidad Nacional Mayor de San Marcos. Docente universitario. (e-mail: igorchong@ hotmail.com).
\end{abstract}

3 Economista. Jefe de Departamento de la Escuela de Economía de la Universidad Nacional de la Amazonía Peruana. Decano del Colegio de Economistas de Loreto. (vladimir.chong@gmail.com).

\begin{abstract}
4 La primera necesidad básica define a las viviendas como inadecuadas si cuentan con piso de tierra y paredes de quincha, piedra con barro, madera o estera. La segunda necesidad básica considera a los hogares que tienen hacinamiento, es decir: si es que en el hogar hay más de 3,4 personas por dormitorio. La tercera necesidad básica considera los hogares que no cuentan con ningún tipo de desagüe. La cuarta necesidad básica considera a los hogares que tienen al menos un niño de seis a doce años que no asiste a la escuela. Finalmente, la quinta necesidad básica considera los hogares con alta dependencia económica, es decir aquellos hogares que cuentan con un jefe de hogar que sólo haya cursado hasta el segundo año de primaria, o con más de 4 personas desempleadas por persona empleada (o con todos los miembros de hogar desempleados).

5 De acuerdo a la OCDE (2001): La eficiencia económica puede entenderse en dos sentidos: eficiencia técnica y eficiencia en la asignación de recursos. La primera es la capacidad de una firma para obtener el máximo producto a partir de un conjunto de insumos (eficiencia técnica de producto) o el uso mínimo de insumos para lograr un determinado nivel de producto (eficiencia técnica de insumos). La segunda es la habilidad de la empresa para utilizar insumos en proporciones óptimas dados sus precios o generar niveles de producto óptimos dado un conjunto de niveles de insumos.
\end{abstract}

6 Representa el presupuesto total para la Región Loreto (Gobiernos regionales y locales). 